\title{
The Human Subsystem - Definition and Integration
}

\author{
Kristian von Bengtson ${ }^{1}$ \\ MOTHER, DK-1422 Copenhagen, Denmark \\ Evan Twyford ${ }^{2}$ \\ MEI Tech. Inc./ NASA Johnson Space Center Houston, TX, USA
}

\begin{abstract}
This paper will discuss the use of the human subsystem in development phases of human space flight. Any space mission has clearly defined subsystems, managed by experts attached to these. Clearly defined subsystems and correct use provide easier and more efficient development for each independent subsystem and for the relation between these subsystems. Furthermore, this paper will argue that a defined subsystem related to humans in space has not always been clearly present, and that correct implementation is perhaps missing, based on experience and survey data. Finally, the authors will discuss why the human subsystem has not been fully integrated, why it must be a mandatory part of the programming, a redefinition of the human subsystem, and suggestions of methods to improve the integration of human factors in the development.
\end{abstract}

\section{Introduction}

$\mathrm{T}$ he development of any space craft is carefully planned with a subsystems layout containing all components and factors. A detailed breakdown of known subsystems related to the space craft and mission scenario ensures a complete task assignment and correct technical relation between the subsystems. Figure 1 shows an example of a top level subsystems breakdown in the development of a spacecraft for a human mission. Each subsystem is directly or indirectly connected to the other.

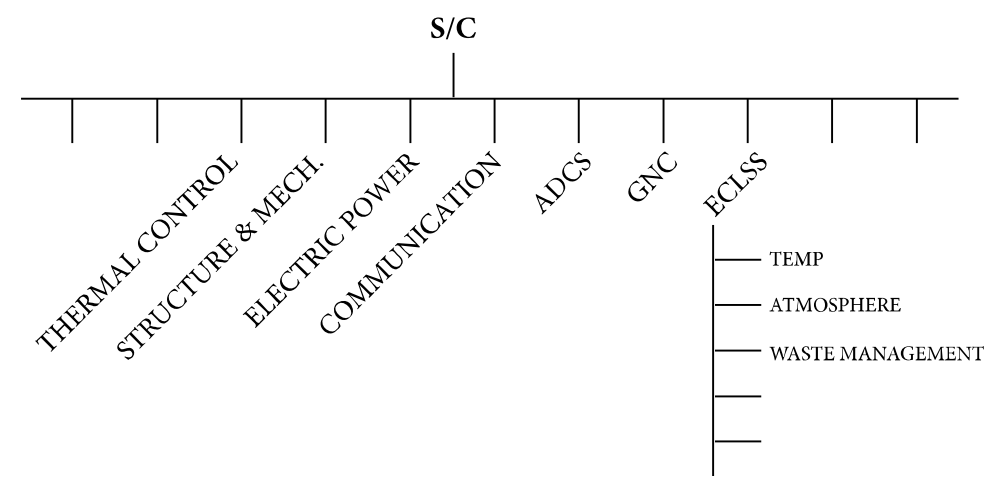

Figure 1. Example of a subsystem breakdown related to human space flight (not complete).

(ADCS = Attitude determination and control, GNC = Guidance and navigation control)

During all development phases, specialists are assigned to one or more subsystems for which they are responsible. Development, reviews and meetings between these specialists are held when needed. This ensures not only correct development, production and operation but also results in the best way of sharing step by step development and internal and external design review presentations, trough up and down the chain of command. Space flight design and engineering must be an exact science. A science with incorrect development, production and

\footnotetext{
${ }^{1}$ M.Arch, M.Sc, Prinsesseagade 7a, st.mf, Copenhagen, Denmark. Member of AIAA, Design Engineering Technical Committee (DETC) Aerospace Architecture Subcommittee (ASASC).

${ }^{2}$ BFA Industrial Design, Rhode Island School of Design, Providence, Rhode Island. Member of Industrial Designer's Society of America (IDSA).
} 
operation will not only result in the loss of equipment, but also loss of life. However, therein lies the conflict, as critical design guidelines, often related to certain human factors, cannot always be best represented by a set of quantifiable data. For the purposes of this paper the authors will refer to this conflict as the 'quality vs. quantity' question, and one will discover that it can be found to exist in the development of almost every manned space craft design.

\section{A. Quality vs. Quantity}

So space flight design must be an exact science. But is all human factors development an exact science? When it comes to certain psychological and sociological factors, the issues can often be measured only in a qualitative matter that can be very difficult to quantify, impossible to quantify or quantifiable only in a very subjective manner. This is the conflict between qualitative and quantitative data and analysis.

Example: It is psychologically desirable to maximize habitable volume to mitigate effects of confinement and sensory deprivation on the human crewmember. The perceived volume is a qualitative property that can often be designed into the vehicle without changing actual physical volume, but how do you measure it? One person may say it feels too small, while another may say it feels too big, and yet another will say it feels just right.

Put another way, how do you measure feelings or perception in a quantifiable manner? It is very difficult to do so when the human is so adaptable and different. The issue becomes compounded when the same engineering community that designs non-crewed systems decides to design crewed space systems, and leaves out critical aspects of the human element.

\section{Consultancy vs. Programming}

The main differences between a non-crewed and crewed space system is: the crew itself, and the environmental control and life support system (ECLSS) supporting the crew. These elements must by definition be considered as some of the most important elements of human space flight. Nevertheless, the authors would like to discuss the case that only the ECLSS is repeatedly added to the system level specifications and not the requirements of the crew it self.

Agencies have taken many steps to ensure the best integration of crew and machine. NASA has created a Human Factors Branch located at Johnson Space Center, with personnel holding the correct expertise in all aspects related to humans in space. One of the early approaches by this branch was to gather all necessary human factors information to be used by anyone who needs to focus on human-machine integration. One major file is the Man-Systems Integration Standards (MSIS); a large document containing relevant data of human performance in space, some based on test in orbit on Skylab. The purpose of MSIS is explained by the following quote at the NASA MSIS website:

The NASA-STD-3000 was created to provide a single, comprehensive document defining all generic requirements for space facilities and related equipment which directly interface with crewmembers. This document provides specific user information to ensure proper integration of human-system interface requirements with those of other aerospace disciplines. ${ }^{1}$

ESA, who does not have a human factors branch, have taken a similar approach, collecting data in open documents for anyone, inside or outside ESA, who require demands and requirements of humans in space. Such a document is HUMEX, amongst many, which provide an overview of human factors particularly in longer mission scenarios ${ }^{2}$. This document is more recent than the MSIS documents, and contains matters of psychology, sociology and behavior, not found in the MSIS documents.

Unfortunately, the commonality of these efforts is that they are merely documents. It is important not to rely too heavily on open documents for additional departments to use, rather than actually engaging the human factors branch to participate in development. By experience of the authors, human factors personnel are more often simply consulted than officially incorporated into the development phases (see more in section 3, B). When such is the case, it tends to result in poor integration of the work done by human factors experts. But more importantly, if a subsystem is not generally accepted and incorporated it will never be understood, making the subsystem even more irrelevant. This could result in human factors inputs becoming a 'nice-to-have' or a 'best practice' rather than a necessary 'need-to-have' element or requirement. 
The authors believe that a human subsystem should officially be incorporated into the development phases of human space flight, for the following reasons:

1) To ensure correct incorporation of appropriately designed man-machine interfaces between crew and vehicle.

2) To ensure better programming, planning, budgeting and communication for human space flight missions development phases.

3) To ensure correct mission-specific demands and requirements incorporation.

4) To understand which areas of the human factors that can and cannot be understood by default assigned parties in order to:

5) Invite new expertise into the human factors area.

If the human factors are indeed far from being incorporated into the development phases, the authors suggest several reasons why this is the case:

1) Tradition: With roots in the space race, space flight began as a demonstration of technological- and political power. The human presence in space was merely a better way to position a country in space. Humans were considered a secondary element to technology itself.

2) A grey area: The human nature, feeling and emotion can be difficult to identify and understand in graphs and charts. Think quality vs. quantity?

3) Adaptation: Humans are exceptionally good at adapting to extreme environments. This skill has perhaps undermined the human role vs. the machines, as it has been widely accepted to view the human as a less important factor, serving and adapting to the machines.

\section{Survey, Inputs and Experience}

\section{A. Survey and inputs}

The authors asked 10 people inside and 8 people outside the human factors field questions about the use of a human subsystem in space flight development. All questions were to be answered with "yes/no/don't know". This was done to provide external opinions to the discussion. The 18 survey participants represent agencies and companies such as NASA, JAXA, Bigelow Aerospace and Jacob Engineering (See appendix, table 2 for complete questionnaire and answers).

Survey answer summary:

- 9 of 10 (related to human factors) feel that a human subsystem is completely or partially missing in development phases of human space flight.

- 8 of 10 (related to human factors) have experienced co-worker expressing that a human subsystem is less or not important in human space flight.

- $\mathbf{7}$ of $\mathbf{1 0}$ (related to human factors) have experienced that their work has been missing or ignored in internal design reviews or presentations.

- 2 of 18 (all survey participants) believe that a subsystem has been fully incorporated into the development phases of human space flight.

\section{B. Experience}

Based on experience of the authors, when assigned to the phase 2 of the lunar lander study team, supporting the lunar lander preparatory study (LLPS) in 2006, Johnsons Space Center, NASA, the following was noted:

- Human factors personnel, assigned to the study, were rarely asked to participate in meeting and design sessions, unless requested by the human factors personnel themselves.

- Work performed by the human factors personnel was rarely requested by the study group and often missing or given low attention in presentations and internal design reviews.

- No presentation and introductions of concepts and mockup, produced by the human factors personnel, for external panel reviewers were done by human factors personnel. This resulted in misunderstanding and (perhaps) poor feedback.

- Human factors personnel are often consulted when questions arose, more than being actively participating. 
Interesting comments were added the survey:

David Fitts, Chief, Habitability and Human Factors Branch, Space Life Sciences, JSC, NASA

I want to devote the next few years of my career here at NASA developing processes, guidelines and requirements that make human factors engineering (or human/systems integration) a mandatory part of program and project engineering design processes.

These results bring a good question to mind. Is the broad store of human factors knowledge that is necessary available in a truly accessible way, or are there properly trained human factors designers available that have all the necessary skills to stand up at equal level with the engineering community? Perhaps there is a capability or a communications gap within the human factors community that causes human as a subsystem to sometimes be excluded. Could it be a case of quality vs. quantity? Whatever the case, everyone must first baseline, what does human as a system mean?

\section{Defining and Integration}

\section{A. Definition}

Correct incorporating of any subsystem requires a correct understanding of the subsystem, which starts with defining and outlining the content. The definition presented in table 1, compiled by the authors, is based on: avoiding unnecessary overlapping with existing subsystems and the relation to human life from a 24 hour clock standpoint but also from a short and long mission duration point of view. Furthermore, the authors suggest that any matter that at some point influences the astronaut's performance, planning or behavior during a mission should be added to the list. Certain matters such as EVA and tools are foremost engineering matters, but should also be included in the human subsystem for crew-machine integration. Conversely, matters pertaining to psychology and sociology seem to be consistently missing from the development process. Could it be due the difficult issues that present themselves when trying to quantify such data?

\section{B. Integration}

The complexity of integrating and handling human factors in space flight development could be minimized by introducing design approaches and doctrines, commonly used in the design and architectural industry:

1) Baseline human factors: Defining (and understanding) the meaning of human factors must be done cooperatively by all participating parties such as engineers, psychologists, architects etc.

2) Recognizing human factors: Every key player attached to the development of human space flight must recognize the importance of human factors. This should be done as a top level requirement.

3) Full subsystem specification: Human factors must be added to the subsystem level specification as a human subsystem. This, plus the above mentioned approach, will allow for the human factors department or personnel to be a part of the development, planning, meeting and design reviews. Consultation on an irregular basis cannot be acceptable.

4) User-driven design, user-centered approach: This design principle should be a mandatory approach in the human factors development phase, leaning more toward a system where machine serves the human, rather than vice versa. This approach will by definition centralize the user (astronaut) in the development and final use.

5) Holistic approach, big thinking: Viewing the whole scenario of human factors in relation to the engineering problems will provide a better overview and better solutions. This includes that qualitative data that can be very difficult to account for.

6) New expertise: The development of human factors must be performed by experts holding the necessary expertise such as architects, designer, psychologists, sociologists, or strategic combinations of such skills. It takes a very specialized skill set to work a user-centered approach in a truly holistic manner. It may be the case that this type of designer has not been properly defined, trained or invented yet, but a combination of design and development skills coupled with broad human factors knowledge, experience, psychology and sociology is a must have! 


\section{Human performance \& Requirements}

Respiration: Oxygen, $\mathrm{CO} 2$

Water: drink, food, hygiene,

Food

Waste: solid, liquid, vapor

Vision

Auditory System

Olfaction and Taste

Vestibular System

Kinesthesia

Reaction Time

Motor Skills

Strength

Workload

Deconditioning

Microgravity Countermeasure

\section{Psychology and Sociology}

Confinement, isolation

Group dynamics: productivity, culture, sex, gender, age, experience

Communication: internal, external

Workload, stress

Personal development

Crew autonomy

Behavioral reactions

Note: the above section is often completely ignored or under-considered.

\section{Crew Safety and health}

General Safety

Mechanical Hazards

Electrical Hazards

Touch Temperature

Fire Protection and Control

Decompression Hazards

Preventive Care

Medical Care

Crew Survival

\section{Architecture}

General Considerations and Requirements

Orientation, location Coding

Envelope Geometry for Crew Functions

Traffic Flow

Translation Paths

Mobility Aids and Restraints Architectural

Interior design

Lighting, color, texture

Hatches, doors and windows
Anthropometric \& Biomechanics

Anthropometrics Considerations

Biomechanics Considerations

Natural and induced environments

Atmosphere, pressure, vacuum

Microgravity

Acceleration

Acoustics

Vibration

Radiation

Thermal Environment

Combined Environmental Effects

\section{Tools}

Drawers and Racks

Closures and Covers

Mounting Hardware

Handles and Grasp Areas

Restraints

Mobility Aids

Fasteners, connectors

Packaging

Crew Personal Equipment

Cable Management

\section{Facilities}

Controls, Displays, Labeling and Coding

Hygiene

Body Waste Management Facilities

Crew Quarters

Galley and Wardroom

Meeting Facility

Recreation Facility

Space Medical Facility

Laundry Facility

Trash Management Facility

Stowage Facility

Management: housekeeping, inventory

Maintenance, repair

\section{EVA}

Physiology

Anthropometry

Workstations and Restraints

Mobility and Translation

Tools, Fasteners, and Connectors

Safety

Table 1. Outlining the human subsystem, compiled by the authors ${ }^{1-13}$. 


\section{Conclusion}

Having explored the use of the human subsystem in the development phases of human space flight, talking with personnel and looking to experience and survey data, it is the opinion of the authors that the human subsystem is far from being fully integrated in the development of most manned space systems and must be viewed equally important as any other subsystem, considering that the human element is what separates non-crewed from crewed space systems. Given the nature of these projects, it must be a mandatory part of the programming. Whether the human data remains too difficult to quantify, or is simply ignored, a more specialized form of human factors specialist is most definitely called for. Given the definition of the human subsystem, and suggestions of methods to improve the integration of human factors in development, one can clearly understand the benefit of incorporating such a user-centric approach to the design and development of space systems where safety and productivity of crewmembers remains the primary factor in mission success. Once again, the human can often adapt to the most extreme of environments, but one will soon find that the solutions yielded by a holistic, human-centered design approach will far exceed the solutions generated by a purely engineering based system, both in quality and quantity.

\section{Appendix}

\begin{tabular}{|c|c|c|c|c|c|c|c|c|c|c|c|c|}
\hline \multicolumn{13}{|c|}{ Human subsystem survey data } \\
\hline $\begin{array}{l}\text { Have you been involved in a human space flight project } \\
\text { where a clearly defined human subsystem has been } \\
\text { completely or partially missing? }\end{array}$ & $\begin{array}{llll}Y & Y & Y\end{array}$ & $Y$ & & Y $\mathrm{Y}$ & $1 \mathrm{~N}$ & & Y & $Y$ & $Y \quad X \quad N$ & & & \\
\hline $\begin{array}{l}\text { Have you ever been involved in a human space flight } \\
\text { project where suggestions and work related to a human } \\
\text { subsystem has been missing or somewhat ignored in } \\
\text { meeting scheduling, presentations or internal design } \\
\text { reviews? }\end{array}$ & $N \quad N \quad Y$ & $\mathrm{~N}$ & & $\mathrm{Y} \mid \mathrm{Y}$ & (1) $\mathrm{Y}$ & & & $Y$ & $\begin{array}{r}Y \\
\mathrm{~N}\end{array}$ & $Y Y$ & & \\
\hline $\begin{array}{l}\text { Do you feel in general that a human subsystem has } \\
\text { already been fully integrated in R\&D of human space } \\
\text { flight? }\end{array}$ & $\mathrm{N} N \mathrm{X}$ & $\mathrm{N} I$ & & & $N \mathrm{~N}$ & & $\Gamma$ & & $\mathrm{X} Y$ & & $\mathrm{X} N$ & N \\
\hline $\begin{array}{l}\text { Have you ever felt that one or more co-workers } \\
\text { participating in the development of human space flight } \\
\text { missions express that a human subsystem is less or not }\end{array}$ & $\mathrm{N} N \mathrm{Y}$ & $\mathrm{Y}$ & & & Y $Y$ & & T & & $N Y Y$ & $\mathrm{Y} \mid \mathrm{Y}$ & & \\
\hline
\end{tabular}

Table 2. Human subsystem questionnaire and answers. ( $Y=$ yes, $N=$ no, $X=$ don’t-know)

\section{Acknowledgments}

Thanks to people at NASA, JAXA, Bigelow Aerospace, AIAA Aerospace Architecture Sub Committee for answering survey questions.

\section{References}

${ }^{1}$ NASA., “Man-Systems Integration Standards Revision B, July 1995,” Man-Systems Integration Standards Revision B, July 1995 [online document], URL: http://www.msis.jsc.nasa.gov [cited July 1995].

${ }^{2}$ European Space Agency, SP-1264: HUMEX Study on the survivability and Adaptation of Humans to Long-Duration Exploration Missions, November 2003.

${ }^{3}$ Freeman, M., Challenges of human space Exploration, $1^{\text {st }}$ ed., Springer, ISBN-10: 1852332018, July 2000.

Bond, R. L. Habitability/Crew Quarters - Experiment M487. Skylab Med. Expt. Altitude Test (SMEAT)/ 11 p. SEE N7411854 03-04. NASA. 1973.

${ }^{4}$ Crane, B. H. The Relationship of Work-rest Schedules, Confinement, and Habitability to Crew Performance as Anticipated for Space Missions, a Selected Review. NASA-CR-126779. NASA. 1964.

${ }^{5}$ Fraser, T. M. The Effects of Confinement as a Factor in Human Space Flight. NASA-CR-511. NASA. 1966.

${ }^{6}$ Hay, G. M.; Loats, H. L., Jr.; Morris, E. Study of the Astronauts Capabilities to Maintain Life Support Systems and Cabin Habitability in Weightless Conditions. NASA-CR-1405; ERA-68-1. NASA. 1969.

${ }^{7}$ Marton, T.; Rudek, F. P.; Miller, R. A.; Norman, D. G. Handbook of Human Engineering Design Data for Reduced Gravity. NASA-CR-1726. NASA. 1971.

${ }^{8}$ Mc Fadden, N. M.; Patton, R. M.; Rathert, G. A., Jr.; Rogers, T. A.; Stinnett, G. W.; Weick, R. F. Minimum Crew Space Habitability for the Lunar Mission. NASA-TN-D-2065. NASA. 1964. 
${ }^{9}$ Mounte, Frances E. Volume Considerations for Future Space Vehicles. Unpublished internal document. NASA.

${ }^{10}$ NASA. Habitability Data Handbook Volume 2 : Architecture and Environment. NASA-TM-X-68352; MSC-03909-VOL1\&2. NASA.1972

${ }^{11}$ Nefedov, Yu. G.; Zaloguyev, S. N. The Problem of Spacecraft Habitability. Space Biol. and Med. Jun. 1967 p34-42 Refs /SEE N67-29205 16-04. 1967.

${ }^{12}$ Petrov, Y.A. Habitability of Spacecraft. NASA, Washington Found. of Space Biol. and Med., Vol. 3/ p 157-192. 1975.

${ }^{13}$ Wise, James A. The Quantitative Modelling of Human Spatial Habitability. NASA-CR-177501; NAS 1.26:177501. NASA. 1988. 